\title{
Assessment of Physicochemical Characteristics of Groundwater Quality used for Drinking Water Supply of Firozabad City, India using Index Method
}

\author{
NIKHAT BANO \\ Department of Geography, \\ Faculty of Science, Aligarh Muslim University, Aligarh, India \\ Corresponding Author E-mail: nikhatamu@gmail.com
}

\begin{abstract}
The aim of the present study is to assess the qualitative aspect of drinking water supply of Firozabad city (India) through index method and comparing it with existing standards for important parameters. The main components of the study include a field sampling analysis of groundwater collected from three different sites viz. Agra Gate (S1), Suhag Nagar (S2) and Raja Ka Tal (S3) and it's Index is calculated from physico-chemical analysis of eight parameters taken together, which ranges from 235.56 to 576.59 indicating the heavy pollution load in water. The present paper also examines the occurrence of diseases in the households of Firozabad city obtained through field survey which shows that malaria, Diarrhea, Gastroenteritis and Cholera are most frequently diseases in the city inhabitants. The paper is concluded with few remedial strategies. OJASEM
\end{abstract}

https://dx.doi.org/10.4314/jasem.v21i4.13

Key Words: Water Quality, Water Quality Index, EIA, Health, Diseases, Firozabad City.

Water is the most essential supporting element for the survival of human life, gives full support in the movement, circulation and cycling of nutrients. It is interesting to note that the requirement of water for various purposes is increasing at a rapid rate on the one hand, while sufficient potable quality of water is deteriorating and its pollution level is going up at a fast rate on the other. However, out of $1500 \mathrm{~km}^{2}$ of water present in the hydrosphere, merely $1 \%$ is available for the fulfillment of the needs of human beings and it is obtainable from such sources as groundwater, river, lakes, soil profile, atmosphere and biological system, though 99\% comes from groundwater (Singh, 2010). Increase in human population has exerted an enormous pressure on the provision of safe drinking water especially in developing countries. Unsafe water is a global public health threat, placing persons at risk for a host of diarrheal and other diseases as well as chemical intoxication. Most of the fresh water bodies all over the world are getting polluted, thus decreasing the portability of water (Etim et al., 2013). In general, the quality of water is equally important as the quantity. Therefore, water quality is considered as an important factor to judge environment changes which are strongly associated with social and economic development (Darapu et al., 2011).

Contamination of groundwater by domestic, industrial effluents and agricultural activity is a serious problem faced by developing countries. The industrial waste water, sewage sludge and solid waste materials are currently being discharged into the environment indiscriminately. These materials enter subsurface aquifers resulting in the pollution of irrigation and drinking water (Girija et al., 2007). Therefore, the assessment of water quality is very important for knowing its suitability for various purposes. Water quality index (WQI) indicates the quality of water in terms of index number for any intended use. It is defined as a rating reflecting the composite influence of different water quality parameters were taken for calculation of water quality index (Rao et al., 2010).

Firozabad city is facing an acute problem of water pollution because of old rusted and leaking water pipe lines and a large gap between demand and supply of water by the Jal Nigam. The core part of the city has no aquifer left and is declared as dark zone by Jal Nigam. Underground water is the only source of water available to the city whereas the city suffers from poor water quality, chocked sewer lines, poor drainage system and water-logging problem etc.

The status of the groundwater depends on a large number of individual physico-chemical parameters and heavy metals. Pollutants are added to the ground water system through anthropogenic activities and natural processes. The uncontrolled industrial and urban activities are the primary cause of the water contamination as the city is surrounded by many glass bangles and glass wares industries and household bangle dying chemical and compressor 
activities and the effluents from these activities are discharged in to the Yamuna River causing impact on the quality of the underground water. Solid wastes of the city is being dumped in an unorganized manner in vacant areas of the cities and subjected to reaction with percolating rain water and reaches the ground water level. The percolating water picks up a large amount of dissolved constituents and reaches the aquifer system and thus it contaminates the ground water. The aim of this paper is assessment of physicochemical characteristics of ground water quality of Firozabad City and to establish relation between the contaminated water quality and reported diseases by the residents of the city.

\section{MATERIALS AND METHODS}

Study Area: Firozabad city covers a part of Doab of Ganga and Yamuna River and occupies central part of the Indo-Gangetic alluvial plain. The city lies between $27^{\circ} 12^{\prime}$ to $27^{0} 18^{\prime}$ North Latitude and $78^{0} 35^{\prime}$ to $78^{0} 42^{\prime}$ East Longitude and occupies the central part of the district. Total geographical area of the District is 2362 sq. $\mathrm{km}$. and the area of the city is 21.35 sq.km. with a population of 603,707 . Since ancient times it is famous for glass products and glass bangle works. Firozabad, where people breathe glass not air, where every second conveyance is found fully stuffed with sparkling glass bangles of intensive colors due to which the city is also known as Suhag Nagri, being a mansion of colorful and glittering bangles, rolling in the laps of rainbow colors, can impress anyone with open wide eyes and a word "Wow" amidst those colorful tiny glass crystals chandeliers. But these colors finally leave the city into hazy atmosphere, floating smoke and strewn garbage, irritating noises. The city is nothing without glass products, glass bangles and glass production units.

Today Firozabad, has more than $85 \%$ of population involved in glass industry directly or indirectly, and produces an estimated 2000 tones of glass products daily, including around 50 million bangles. The bangle-making industry comprises tier upon tier of units whose activities are closely interlinked. At the apex are open pot furnace units that produce molten glass and 'raw' bangles; below them are thousands of household-level units in which these raw bangles are processed; finally there are hundreds of muffle furnaces (pakai bhattis) units in which the processed bangles are annealed to yield the finished products.

Large quantity of water is also used in glass making process especially during molding, cooling, washing and edge glazing that are drained out without treatment leading to land and underground water contamination. The quality of water is decreasing continuously and is posing a great threat to all forms of life including humans. Polluted water is the major cause for the spread of many epidemics and some serious diseases like cholera, tuberculosis, typhoid, diarrhea etc.

Sampling: Water samples were collected in pre cleaned plastic bottles of 2 liters and were analyzed for water quality parameters like $\mathrm{pH}$, electrical conductivity, total dissolved solids, total hardness, total alkalinity, calcium magnesium and chlorides as per standard method 2002. Water samples of bore well were collected from three selected sites namely Agra Gate (S1), Suhag Nagar (S2) and Raja Ka Tal (S3).

Data Analysis: In this study, for the calculation of water quality index, eight important parameters were chosen. The WQI has been calculated by using the standards of drinking water quality recommended by the Indian Council of Medical Research (ICMR) and Bureau of Indian Standards (BIS).

The overall Water Quality Index calculated by aggregating the quality rating with the unit weight linearly (Brown et al., 1970).

$$
W Q I=\sum q n * w n \div \sum w n
$$

In this study, the computed grads of WQI values were categorized into five types for human consumption according to (Ramakrishniah et al., 2009), as they were revealed in (Table 1) WQI indicates the quality of water in terms of index number which represents overall quality of water for any intended use.

Table 1: Water Quality Index Grades (WQI) and status of water quality (Ramakrishniah, Sadashivaiah and Ranganna 2009)

\begin{tabular}{ll}
\hline Water Quality Index Levels & Description \\
\hline$<\mathbf{5 0}$ & Excellent \\
$\mathbf{5 0 - 1 0 0}$ & Good water \\
$\mathbf{1 0 0 - 2 0 0}$ & Poor water \\
$\mathbf{2 0 0 - 3 0 0}$ & Very poor (bad) water \\
$>\mathbf{3 0 0}$ & Unsuitable and Unfit for drinking \\
\hline
\end{tabular}


Data Collection through Field Survey: Primary source of data is obtained from a comprehensive survey conducted from May 2012 to October 2013 with the help of a questionnaire regarding health profile of the people. Data is collected from 42 wards through purposive random sampling method. In all 3050 heads of the household have been interviewed from entire wards, forming 3 percent sample of the total households of each ward. The strategy adopted for the selection of the household has been purposive random as the houses where compressor work on bangle and houses near to Pakkai Bhattis and beyond the range of 15-20 meters are taken into considerations as the city is an industrial area, apart from large industrial units where only glass is made from raw material; the whole city is netted with household industry that act as supporting unit in final production to marketing of the glass and bangles.
Type and location of the house has also been taken into considerations.

The information obtained is organized, categorized and analyzed using Microsoft Excel version 2010 (average and percentage) which is also used to design various charts, figures and Arcview 3.2 for maps.

\section{RESULTS AND DISCUSSION}

Environmental Impact Assessment of Water Quality Status: The average results of the physico-chemical parameters for water samples are presented in Table 2. The analysis clearly reveals that most of the parameters of the water sample do not comply with WHO and Indian Standards recommendations (Table 2) and are reported to be beyond the prescribed limit which is not a good sign for consumption

Table 2: Average results of the Physico-chemical Parameters (July-Dec 2012)

\begin{tabular}{|c|c|c|c|c|c|c|}
\hline \multirow[t]{2}{*}{ Sl.no. } & \multirow[t]{2}{*}{ Parameters } & \multicolumn{3}{|c|}{ Sampling Sites } & \multirow[t]{2}{*}{ WHO (2002) } & \multirow[t]{2}{*}{ IS (10500-91) } \\
\hline & & $\mathrm{S} 1$ & $\mathrm{~S} 2$ & S3 & & \\
\hline 1 & $\mathrm{pH}$ & 7.82 & 7.464 & 7.80 & $6.5-9.5$ & $6.5-8.5$ \\
\hline 2 & $\mathrm{EC}$ & 2483.20 & 1319.8 & 968.00 & 250 & NI \\
\hline 3 & TDS & 1766.40 & 909.4 & 653.60 & 1500 & 500 \\
\hline 4 & $\mathrm{TH}$ & 1286.40 & 358.4 & 264.60 & $150-500$ & 300 \\
\hline 5 & TA & 193.60 & 213.2 & 208.00 & 250 & 200 \\
\hline 6 & $\mathrm{Ca}^{++}$ & 1066.40 & 268 & 118.20 & 100 & 75 \\
\hline 7 & $\mathrm{Mg}^{++}$ & 220.00 & 90.4 & 136.80 & 50 & 30 \\
\hline 8 & $\mathrm{Cl}^{-}$ & 982.60 & 130.4 & 53.80 & 250 & 250 \\
\hline 9 & $\mathrm{TC}$ & 12.60 & 10.2 & 6.00 & NI & NI \\
\hline
\end{tabular}

All parameters are in mg/l except $\mathrm{pH}, \mathrm{EC}$ and TC, EC in micromhos/cm, TC in MPN. NI: NO Indection Source: Based on Field Survey 2012-2013.

Water Quality Index (WQI) Result: However, on the basis of WQI, it can be seen that the analysis of experimental investigation on quality of groundwater using physico-chemical parameters of the study area indicates that the quality of water in terms of index number is very poor to unsuitable or unfit for drinking purpose (Table 3).

Table 3: Water Quality Index of Selected Sites

\begin{tabular}{ccc}
\hline SL.No. & Sites & Water Quality Index Value \\
\hline 1 & Agra gate (s1) & 576.59 \\
2 & Suhag nagar (s2) & 284.78 \\
3 & Raja ka Tal (s3) & 235.56 \\
\hline
\end{tabular}

Source: $\overline{\text { Computed by author on the basis of physic-chemical analysis }}$

The categorization of water quality with respect to its WQI values is shown in table 1 . The index values reveal that the status of water at Agra gate (576.59) is unfit according to WHO guideline standards (Ramakrishniah, et al., 2009). Contrary to this, the WQI values for the sampling sites S2 (Suhag Nagar) and S3 (Raja ka Tal) is 284.78 and 235.56 respectively, indicating very bad water (200-300).

Household Environmental Quality (Water) and Health: It has been observed that water supply and sanitation condition of the city is affecting the health of the people. The resident of the city are mostly dependent on the municipal supply of water for all of their needs and the water distribution system of the city has become old due to which the rusted pipe line running parallel to the drains suck sludge and contaminated water of the drain and furthermore multiple connection into single supply line makes the condition more worst, when people consume this contaminated untreated water their health is affected (Table 4). It has been also reported that private submersibles are owned by few, who have high economic status whereas medium to low income 
group people rely on the municipal supply as well as government bored mark II hand pumps at few locations basically at the outer rim of the city because aquifer has dried up at the central part of the city. The analysis reveals that Malaria is reported by largest number of respondent's (66.36) followed by
Diarrhea (51.01), Gastroenteritis (50.13), Cholera (35.01) and Jaundice (34.09) whereas Amoebiasis is resorted by 10.65 per cent of respondents, hepatitis by 12.28 per cent and least number of Fileriasis i.e. 8.84 per cent (Figure 2).

Table 7: Most Frequently Reported Diseases in Respondent's family (\%) in Firozabad City

\begin{tabular}{ccccccccc}
\hline Categories & Malaria & Fileriasis & Hepatitis & Jaundice & Diarrhea & Cholera & Gastroenteritis & Amoebiasis \\
\hline High & 91.37 & 25.20 & 32.57 & 53.82 & 78.81 & 67.69 & 71.21 & 31.24 \\
Medium & 66.29 & 12.03 & 13.12 & 33.73 & 53.55 & 34.09 & 50.35 & 11.26 \\
Low & 37.82 & 0.01 & 0.00 & 13.30 & 26.23 & 14.25 & 31.98 & 0.00 \\
Total & 66.36 & 8.84 & 12.28 & 34.09 & 51.01 & 35.01 & 50.13 & 10.65 \\
\hline
\end{tabular}

Source: Based on field survey 2012-2013.

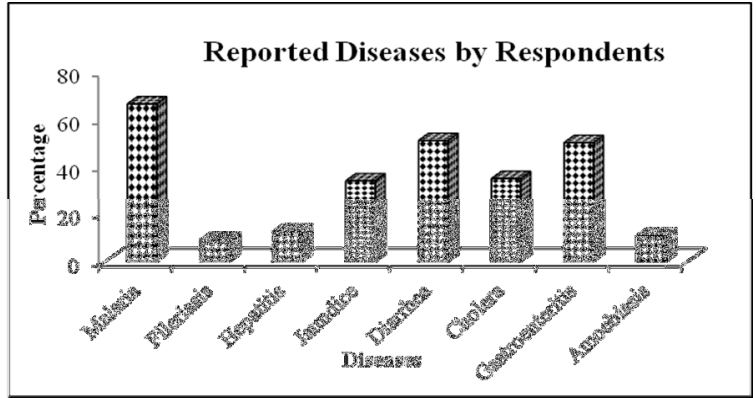

Fig 4: Percent of Respondents Reporting Diseases

Conclusion: The above discussion makes it clear that high household water supply and sanitation problem is mainly found in slum areas and where the labour class resides. High incidence of disease are due to the contaminated watersupply system as the water pipe line are moving through the drains and are damaged from several points thus sucking slug with it. Low water related problems and hence occurrences of disease are observed in areas that are inhabited by high status people, majestic house, good and closed drainage system, no water logging problems and use RO water for drinking as well as good cleaning facility by municipality. Therefore it is recommended to replace the old pipe network with new one, closed drainage system, regular monitoring and maintenance of water pipelines be done for ensuring the adequate water both qualitatively and safe last but not the least, transparency of municipal body in providing sanitary services to lower income wards and slum areas.

\section{REFERENCES}

Darapu, Er.SSK; Sudhakar, Er.B; Krishna, KSR; Rao, PV; Shekhar, MC (2011). Determining Water Quality Index for the Evaluation of water Quality of River. International Journal of Engineering Research and applications (IJERA). 1(2): 174-182.
Etim, EE; Odoh, R; Itodo, AU; Umoh, SD; Lawal, U (2013). Water Quality Index for the Assessment of Water Quality from Different Sources in the Niger Delta Region of Nigeria. Frontiers in Science. 3(3): 89-95.

Girija, TR; Mahanta, C; Chandramouli, V (2007). Water Quality Assessment of an untreated effluent impacted urban stream: the Bharalu Tributary of the Brahamaputra River, India. Environmental Monitoring and Assessment. 221236.

Singh, L (2010). Environmental Geography. APH Publlishing Corporation, New Delhi, 250-251.

Ramakrishniah, CR; Sadashivaiah, C; Ranganna, G (2009). Assessment of Water Quality Index for the Groundwater in Tumkur Taluk. E-Journal of Chemistry. 6(2): 523-530.

Rao, CS; Rao, BS; Hariharan, AVLNSH; Bharathi, NM (2010). Determination of water quality index of some areas in Guntur district Andhra Pradesh. International Journal of Applied Biology and Pharmaceutical Technology. 1(1): 79-86. 